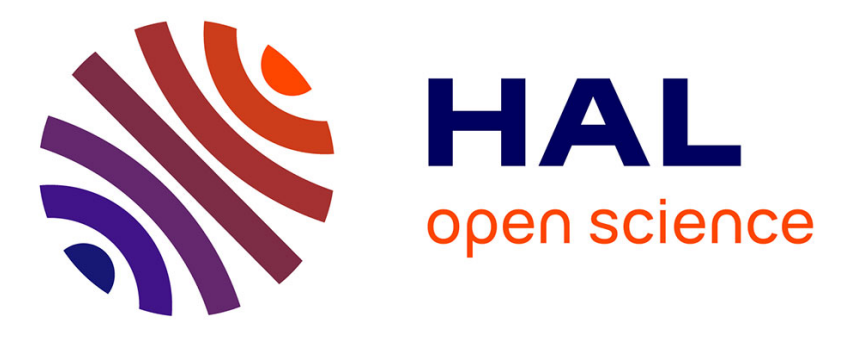

\title{
Influence of depressive symptoms on memory in transient global amnesia.
}

Audrey Noël, Peggy Quinette, Jacques Dayan, Vincent de La Sayette, Fausto Viader, Béatrice Desgranges, Bénédicte Giffard, Francis Eustache

\section{- To cite this version:}

Audrey Noël, Peggy Quinette, Jacques Dayan, Vincent de La Sayette, Fausto Viader, et al.. Influence of depressive symptoms on memory in transient global amnesia.. Journal of neuropsychology, 2015, pp.1-30. 10.1111/jnp.12080 . inserm-01187772

\section{HAL Id: inserm-01187772 https://www.hal.inserm.fr/inserm-01187772}

Submitted on 27 Aug 2015

HAL is a multi-disciplinary open access archive for the deposit and dissemination of scientific research documents, whether they are published or not. The documents may come from teaching and research institutions in France or abroad, or from public or private research centers.
L'archive ouverte pluridisciplinaire HAL, est destinée au dépôt et à la diffusion de documents scientifiques de niveau recherche, publiés ou non, émanant des établissements d'enseignement et de recherche français ou étrangers, des laboratoires publics ou privés. 


\section{Influence of depressive symptoms on memory in transient global}

\section{amnesia.}

Audrey Noël, ${ }^{1,2,3,4,5,6}$ Peggy Quinette, ${ }^{1,2,3,4}$ Jacques Dayan, ${ }^{1,2,3,4,7}$ Vincent de la Sayette, ${ }^{1,2,3,4}$ Fausto Viader, ${ }^{1,2,3,4}$ Béatrice Desgranges, ${ }^{1,2,3,4}$ Bénédicte Giffard, ${ }^{1,2,3,4}$ and Francis

$$
\text { Eustache } \mathrm{e}^{1,2,3,4^{*}}
$$

${ }^{1}$ UMR-S1077, INSERM, Caen, France

${ }^{2}$ UMR-S 1077, Université de Caen Basse-Normandie, Caen, France

${ }^{3}$ UMR-S 1077, Ecole Pratique des Hautes Etudes, Caen, France

${ }^{4}$ UMR-S 1077, Caen University Hospital, Caen, France

${ }^{5}$ EA 1285, CRPCC, Rennes, France

${ }^{6}$ EA 1285, Université Rennes 2, Rennes, France

${ }^{7}$ Guillaume Régnier University Hospital, Rennes, France

Word count: 4792 words

Acknowledgments: This study was funded by Caen University Hospital, as part of a clinical research project, and by the Servier laboratory. The authors would like to thank Dr Sophie Marquis and the staff of the emergency unit at Caen University Hospital for their invaluable assistance and Elizabeth Portier for reviewing the English style.

* Correspondence should be addressed to Francis Eustache, Laboratoire de

Neuropsychologie, Inserm - EPHE - UNICAEN U1077, CHU de CAEN, 14033 Caen,

France (e-mail address: francis.eustache@inserm.fr) 


\section{Abstract (250/250)}

Introduction: Recent studies have shown that patients with transient global amnesia (TGA) experience a depressive mood during the episode. However, little evidence has been found of possible mood congruency effects on memory, which are probably masked by the massive anterograde amnesia. An implicit assessment could provide a means of settling this question.

Methods: First, we measured patients' emotional states on psychopathological scales. Second, we administered a lexical decision task to assess three priming effects: semantic priming (SP; table-chair), emotional priming (EP; murder-garbage), and emotional plus semantic priming (ESP; cemetery-coffin).

Results: Patients displayed a more depressed mood than controls. For patients, we found a semantic priming effect in the ESP condition, and a striking inhibition effect (i.e. negative target recognized more slowly when preceded by a negative prime rather than a neutral one) in the EP condition. For controls, a priming effect was found in the SP and ESP conditions, but not the EP condition. Finally, whereas the priming effect was greater in SP than in the other two conditions for controls, for patients it was the EP condition that stood out from the other two, being the only condition that led to an inhibition effect.

Conclusions: We highlighted a mood congruency effect in TGA which could impel patients to focus their attention on negative information. While the negative valence of items always led to a slowdown in reaction times for both patients and controls, attesting to a negativity bias, this bias was greater in patients, leading to an inhibition effect. 
Transient global amnesia (TGA) is a selective memory disorder that occurs in middle age and lasts just a few hours. It is characterized by the sudden onset of anterograde amnesia, usually accompanied by variable retrograde amnesia and repetitive questioning, and is thought to be caused by a functional disturbance of the hippocampus (Bartsch \& Deuschl, 2010). Before the 1950s, TGA was often regarded as a psychiatric illness (Hodges, 1991), because it shared some characteristics with hysteria (sudden onset, emotional precipitants, anxiety and depressive symptoms). However, most recent research on TGA has focused on the neuropsychology of memory and pathophysiology (Noël et al., 2015).

Although several authors (Kritchevsky, Squire, \& Zouzounis, 1988; Laurent, 1991; Schmidtke \& Ehmsen, 1998; Schott, 1969) have drawn attention to a context of psychological strain prior to the episode and abnormal behavior tinged with anxiety during the episode, only a handful of studies have specifically investigated the presence of emotional symptoms in TGA. The first study to thoroughly assess the presence of emotional symptoms was carried out by Inzitari et al. (1997). Their main finding was that patients with TGA displayed symptoms similar to those exhibited during a panic attack, and had a history of agoraphobic behaviors. This led the authors to surmise that phobic personality traits may constitute a predisposing factor for TGA. In order to confirm this hypothesis, Quinette et al., (2006) conducted a study based on the clinical data of 63 patients. By running a hierarchical classification analysis on these clinical data, they were able to identify at least three prototypical profiles of TGA, associated with different risk factors. One of these profiles was characterized by the presence of emotional symptoms (anxiety or depressive symptoms, emotional instability) or traits belonging to personality disorders. Thus, a psychological vulnerability could lie behind a TGA episode, at least in a subgroup of patients. These results lend weight to the concept of emotional arousal-induced transient global amnesia (Merriam, 
Wyszynski, \& Betzler, 1992), and emphasize the involvement of emotional and psychopathological factors in the triggering of TGA.

As far as more specific depressive symptoms are concerned, Noël et al. (2008) led a study to determine whether these symptoms intervene solely before the episode (i.e., as a predisposing factor) or also during the acute phase (i.e., one of the symptoms of TGA). Results of this study showed that TGA includes sudden changes in people's emotional states, notably an increase in depressive symptoms during the acute phase, whereas only one subgroup of patients with TGA displays emotional symptoms before the episode. This change could, of course, be explained by the mere fact of being admitted to hospital, especially since patients' stereotypical iterative questions refer precisely to their presence in hospital and to the causes of their hospitalization (Hainselin et al., 2012). These symptoms could be also due to feeling of disorientation produced by anterograde amnesia (Noël et al., 2015). Indeed, even if patients are unable to identify the nature of cognitive deficits, they are conscious that something is wrong (Hainselin et al., 2012). Finally, another hypothesis suggests that these emotional changes could rather be regarded as a genuine symptom of TGA, as they follow the same dynamics as the memory disorders. Indeed, the depressive symptoms occur very suddenly, and improve during the recovery phase in exactly the same way as the memory impairments. Moreover, the brain dysfunction observed in TGA (hypoperfusion or hypometabolism of the amygdala and prefrontal regions; Baron et al., 1994; Guillery et al., 2002) concerns brain regions implicated in both memory and mood disorders.

The depressive symptoms can influence the memory performances of patients with TGA in two ways. First, several studies (Ramponi, Barnard, \& Nimmo-Smith, 2004; Yeung, Dalgleish, Golden, \& Schartau, 2006) have shown that depressive patients perform more poorly than controls on tasks assessing the anterograde and retrograde components of episodic memory. In TGA, it has already observed a deleterious effect of depressive mood on 
performances for the anterograde component of episodic memory (i.e., the more depressed the patients' mood, the less accurate their recognition performances; Noël et al., 2008). A second effect on cognition has been observed in mood disorders. This effect, known as the mood congruency effect, is characterized by the preferential processing of items according to the individual's emotional state (Lewis, Critchley, Smith, \& Dolan, 2005). This is why the authors of this study used emotional material (Noël et al., 2008). They expected to observe a mood congruency effect in the tasks assessing both the anterograde (i.e., enhanced processing of negative vs. positive and neutral items in a recognition task) and retrograde (i.e., preferential production of negative memories) components of episodic memory. Concerning the anterograde component, they failed to find a mood congruency effect, and attributed this absence of effect to masking by the extensive anterograde amnesia (floor effect in recognition tasks, whatever the valence of the items). They did, however, find a mood congruency effect in the retrograde memory task, even if patients also had difficulty with this task (though less so than in the recognition task). Patients supplied more negative memories than controls for the most recent life period (i.e., the previous 12 months).

The presence of depressive symptoms has also been held responsible for the persistence of memory disorders beyond the TGA episode. For example, Néri et al. (1995) reported a high rate of depressive symptoms (46\%) in patients examined several months after TGA. They also observed that most of the patients with slight persistent episodic memory deficits were also depressed at the time of the examination. Several months after the episode, Noël et al. (2011) did not find differences between mood of patients and those of controls again, but scores of patients' memory tests were nevertheless correlated to those of mood scale (the more patients mood was negative, the more their performances in memory tests were weak) . Closer to the TGA episode (next day), Noël et al. (2007) observed that only some of the patients with TGA still displayed anxious and/or depressive symptoms. 
Furthermore, only this subgroup of patients had persistent memory deficits-more specifically, difficulty recognizing one particular category of items (i.e., negative ones). These same patients produced less specific, less intense and more negative memories for the lifetime period corresponding to the reminiscence bump (i.e., when patients were aged between 18 and 30 years-a lifetime period that is typically rich in detailed and happy memories). These data support the hypothesis of a mood congruency effect, but are of limited relevance, as the subset of patients who displayed anxious and/or depressive symptoms only comprised four patients.

The results of these studies prompted us to pursue this research, paying particular attention to the time and nature of the assessment. As the depressive symptoms seem to quickly regress after the episode, we chose to carry out our assessment during the acute or peri-acute phase. This choice led us to opt for an assessment of implicit memory, as this measurement is not affected in TGA (Beauregard, Weiner, Gold, \& Chertkow, 1997; Eustache et al., 1997; Guillery et al., 2001). We chose a lexical decision task derived from the paradigm devised by Giffard, Laisney, Eustache, and Desgranges (2009) and Giffard et al. (in press). This task makes it possible to observe semantic priming effects whereby a target (e.g., chair) is recognized faster if it is preceded by a semantically related prime (e.g., table), rather than an unrelated one (e.g., horse). This phenomenon can be explained by the automatic spreading of activation through the prime's semantic network. Thus, concepts related to this prime are pre-activated and therefore recognized faster than unrelated concepts. However, departing from Giffard et al. (2009)'s paradigm, we did not use positive items, as we were interested in interactions between depressive mood and memory performances in TGA. Accordingly, we only needed to compare the implicit processing of negative and neutral items to show mood congruency effects. To maximize our chances of observing semantic priming effects with negative words, we controlled several factors that are known to have an impact on priming. We therefore chose a lexical decision task rather than an evaluative task (thereby 
avoiding an emphasis on the primes' negative nature) with a short stimulus onset asynchrony (SOA) of $250 \mathrm{~ms}$, to avoid participants becoming aware of the link between the prime and the target (involvement of explicit processes). Finally, as we used negative words, we also took the patients' emotional state into consideration. Thus, as priming effects are preserved both in TGA (Beauregard et al., 1997; Eustache et al., 1997; Guillery et al., 2001) and in depression (Dannlowski et al., 2006b), we expected to observe normal semantic priming (SP) and emotional plus semantic priming (ESP) effects (i.e., a facilitation effect when the prime is semantically related to the target, with the latter being recognized faster) in patients whatever the valence of the words (neutral items for semantic priming and negative items for emotional plus semantic priming). By contrast, we expected to observe an inhibition effect in the emotional priming (EP) condition (i.e., when prime and target only share an emotional link without semantic link), with slower responses to targets when they were preceded by a negative prime rather than by a neutral one. According to Dijksterhuis and Aarts (2003), negative information is processed more elaborately than other stimuli. In the case of priming, we therefore reasoned that a negative prime would require more time to be processed, and therefore slow down the response to the target. This inhibition effect had already been observed in depressive patients (Dannlowski et al., 2006b).

\section{Methods}

\section{Participants}

We recruited nine patients ( 6 men and 3 women, mean age $=58.1 \pm 8.9$ years $)$. They were examined during either the acute phase of the TGA episode or the peri-acute one (recovery phase characterized by manifest memory disorders but no disorientation or repetitive questions). All patients met the criteria for TGA published by Hodges and Warlow (1990), and patient selection was systematically carried out by senior neurologists, in line 
with codified procedure. All additional medical examinations, such as brain CT scans and electroencephalograms, were normal. To define the context in which the episode had been triggered, we looked for the presence of precipitants, risk factors and associated symptoms (Table 1). Only one patient (patient 1) had had a previous TGA episode. These 9 patients belonged to a larger cohort of patients included in another study (Noël et al., 2008), which focused on episodic memory impairments.

A control group consisted of 15 strictly selected healthy people, matched with the patient group for age (control group mean age $=62.4 \pm 5.6$ years) and level of education, in terms of the number of years spent at school (control group mean $=11.8 \pm 4.1$ years, patient group mean $=10.6 \pm 2.7$ years).

All the participants gave their informed consent to take part in the study, which was conducted in compliance with the Declaration of Helsinki. This study was approved by the local ethics committee.

[Insert Table 1]

\section{General cognitive function}

In the general cognitive assessment, we assessed orientation and general knowledge, using three subtests (spatiotemporal orientation, semantic categorization, and categorical fluency) taken from the Mattis Dementia Rating Scale.

\section{Psychopathological assessment}

Depressive mood was measured on two scales: the abridged version of the Beck Depression Inventory (BDI; Beck, Rial, \& Rickets, 1974) and the Befindlichkeits-Skala (BfS) or Adjective Mood Scale (Von Zerssen, Koeller, \& Rey, 1970; for more details, see Noël et al., 2008). The abridged version of the BDI was used to assess the level of depressive 
symptoms two weeks before the episode, whereas the Bf-S estimated it at the time of the episode. Because TGA is a short-lived syndrome, we chose scales that did not take long to complete. For both these scales, the higher the score, the more depressed the patient.

\section{Neuropsychological assessment with emotional material}

\section{Episodic memory task}

This task allowed us both to confirm that patients displayed episodic memory disorders at the time of the assessment (i.e., that they were still in the acute or peri-acute phase). It consisted of a yes/no recognition task comprising emotional words. During the study session, participants had to memorize a list of 10 positive, 10 negative and 10 neutral words (intentional encoding) and rate their emotional valence (for more details, see Noël et al., 2008). The test session took place 5 minutes later. We calculated a recognition score for each valence list (positive, negative and neutral items) using Gardiner's procedure $\left(A^{\prime}=1 / 2+\right.$ $[[(\mathrm{Hit}-\mathrm{FA})(1+\mathrm{Hit}-\mathrm{FA})] / 4 \mathrm{Hit}(1-\mathrm{FA})] ; \mathrm{FA}=$ false alarm; Gardiner, Ramponi, \& Richardson-Klavehn, 2002).

\section{Emotional priming task}

\section{Stimuli}

The lexical decision task was composed of 424 pairs of stimuli: 44 pairs with a semantic relationship between either neutral words (e.g., box-package) or negative ones (e.g., cut-gash); 112 pairs without any semantic relationship between either a neutral prime and a neutral target (e.g., door-bag) or a negative prime and a negative target (e.g., threat-sadness), 56 pairs without any semantic or emotional relationship, that is, with a neutral prime and a negative target (e.g., piece-spider) and 212 word/nonword pairs (e.g., notebook-gaton). To 
minimize postlexical attentional processes, the likelihood of encountering a word versus a nonword in the target position was 50\%, and in the pairs where the target was a word, $20 \%$ were semantically related.

To select these word pairs, we carried out a pre-test. A total of 136 healthy volunteers aged 50-91 years judged the affective valence of 576 words on a scale ranging from 1 (highly negative) to 8 (highly positive), and wrote the first three words that came into their heads when they saw each word. We selected the word pairs from these data. Moreover, all the words were matched for frequency and length in each condition (Lexique lexical database for French; New, Pallier, Ferrand, \& Matos, 2001). Most of the words were concrete in all conditions.

\section{Procedure}

The priming task was performed on a computer. Stimuli were presented using SuperLab 1.68 software (Cedrus Corporation, Phoenix, AZ, United States). For each trial, a fixation cross appeared centrally for $500 \mathrm{~ms}$, followed by the prime for $225 \mathrm{~ms}$ and an interstimulus interval of $25 \mathrm{~ms}$, resulting in a short SOA equal to $250 \mathrm{~ms}$ (thus preventing participants from anticipating the nature of the target). The target stimulus remained on the screen until the participant had responded. The screen remained blank for $1000 \mathrm{~ms}$ before the following trial. In order to enhance the automaticity of the task, we asked participants to respond as quickly as possible, but without compromising accuracy. Participants were told how to make a lexical decision using the yes/no method (i.e., respond by pressing one button if the target is a real word and the other button if the target is a nonword).

As this task required a combination of attention and quickness, it was divided into four blocks, each lasting about 5 minutes and separated by a few minutes' interval. Before the beginning of the experiment, participants underwent a practice session featuring 30 items. 
On the basis of response times (RTs) in the five word pair conditions, we calculated three priming effects: SP effect with neutral words (RTs for unrelated neutral prime and neutral target condition vs. RTs for neutral related condition, e.g., jar-carpet vs. lamp-bulb), ESP effect (RTs for unrelated neutral prime and negative target condition vs. RTs for negative related condition, e.g., house-viper vs. mistake-error), and EP effect (RTs for unrelated neutral prime and negative target condition vs. RTs for negative unrelated condition, e.g., house-viper vs. handcuffs-snake). Moreover, to determine whether the mere presentation of a negative word was enough to induce a negativity bias (i.e., longer RTs after the presentation of a negative target without any semantic or emotional link with the prime), we compared the RTs in the neutral unrelated prime and target condition (e.g., jar-carpet) with those in the unrelated neutral prime and negative target condition (e.g., house-viper).

\section{Results}

\section{General cognitive function}

To determine whether patients displayed cognitive deficits, we ran Mann-Whitney $U$ tests comparing their performances with those of controls. There was a significant group effect for the orientation subtest, $U(22)=2.79, p=.02$, confirming that patients were disoriented during the episode. Results of the semantic categorization task were normal, $U(22)=1.58, p=.12$. The numbers of correct responses and perseverative errors on the categorical fluency task differed significantly between the two groups, $U(22)=2, p=.04$, and $U(22)=-3.06, p=.01$, respectively. Patients provided fewer correct responses and more perseverative errors than controls.

\section{Psychopathological assessment}


There was no significant difference between patients and controls for the BDI scores, $U(22)=.03, p=.74$. By contrast, there was a significant group effect on the scores on the Bf$\mathrm{S}, U(21)=-3.20, p=.001$, meaning than patients present more depressive symptoms than controls at the time of examination (i.e., during the attack).

\section{Neuropsychological assessment}

\section{Episodic memory task}

We observed a significant difference between patients and controls, whatever the valence of the words: positive, $U(22)=2.55, p=.01$; negative, $U(22)=2.23, p=.03$; neutral, $U(22)=3.88, p<.001$. Patients recognized fewer items than controls.

\section{Priming effects}

To calculate the priming effect, we looked solely at the yes responses (i.e., we ignored the nonword condition). In order to ensure that results did not depend on extreme scores, in each condition, we excluded responses that were more than three standard deviations (SDs) above or below each participant's mean (which corresponded to $1.4 \%$ of data in controls and $1.2 \%$ of data in patients), and recalculated the mean RTs. Likewise, errors were excluded from the RT analyses. These ones represented $0.8 \%$ of data in controls and $1.4 \%$ of data in patients. Overall, $2.2 \%$ of responses were excluded in controls and $2.6 \%$ in patients. To determine the existence of a significant priming effect (Table 2), we compared unrelated and related conditions by means of nonparametric tests in patients and controls (Wilcoxon tests).

The controls' RTs were faster when neutral items were semantically related than when they were semantically unrelated, attesting to an SP effect for neutral words, $z(14)=3.24, p=$ .001. This effect was not significant in patients, $z(8)=1.60, p=.11$. In the ESP condition, both patients and controls responded significantly faster when the negative prime and 
negative target were semantically related than when they were unrelated, $z(8)=2.31, p=.02$, and $z(14)=2.04, p=.04$, respectively. In the EP (no semantic link) condition, there was a marginal effect, $z(8)=1.84, p=.067$, showing that patients responded more slowly when the prime and target were both negative than when the prime was neutral and the target negative, reflecting an inhibition effect. This effect was not significant in controls, $z(14)=0.34, p=.73$. Finally, the mere presentation of negative target was not sufficient to induce a negativity bias in patients, $z(8)=0.89, p=.37$ and controls, $z(14)=1.14, p=.26$.

[Insert Table 2]

We compared patients and controls on the magnitude of priming effects (Fig. 1), using the Mann-Whitney test. There was no group effect in either the SP condition, $U(22)=.63, p=$ .53 , or the ESP one, $U(22)=-.33, p=.74$. By contrast, there was a significant difference between patients and controls in the EP condition, $U(22)=1.94, p=.05$, where the magnitude of the inhibition effect was greater in patients than in controls.

Finally, we compared the different priming conditions (SP, ESP, EP) within each group, using a Freidman analysis of variance (ANOVA). In controls, we found a significant difference between the three conditions, $\chi^{2}(2)=15.06, p=.004$. A post hoc analysis revealed that priming effects were greater in the SP condition than in either the $\operatorname{ESP}(p=.02)$ or $\operatorname{EP}(p$ $=.001)$ conditions. There was a marginal difference between the two conditions featuring negative words (ESP and EP, $p=.09$ ). In patients, there was also a significant difference between the three conditions, $\chi^{2}(2)=6.22, p=.04$. Post hoc analysis showed that the EP condition differed from semantic priming with both neutral (SP, $p=.04)$ and negative (ESP, $p$ $=.01)$ words. The EP effect was negative (inhibition effect), whereas the semantic priming effects (SP and ESP) were positive (facilitation effect). There was no difference between the two semantic priming conditions (SP and ESP, $p=.59$ ). 


\section{[Insert Figure 1]}

\section{Discussion}

The objective of this study was to gain a better understanding of the impact of mood on cognitive processes during a TGA episode. The results of our study showed that patients with TGA displayed more depressive symptoms than controls during the attack using the BfS, an instrument specifically elaborated to assess fluctuations of mood in a short interval of time contrary to the BDI that assessed depressive symptoms during the two previous weeks. Regarding episodic memory, patients recalled very few words, whatever the valence of the items. As expected, the magnitude of the anterograde amnesia in these patients masked any mood congruency effect. By contrast, the priming paradigm did yield evidence of a mood congruency effect in TGA. To sum up, semantic priming was present in controls whatever the condition (SP and ESP). In patients, however, this semantic priming effect was only significant in the ESP condition. In the EP condition, there was no priming effect in the control group, but we observed a reversed priming effect (i.e., inhibition effect) in patients. Moreover, the magnitude of the priming effects differed between patients and controls. In controls, all the conditions differed, as priming effects were greater in the SP condition than in the ESP one, and greater in the ESP condition than in the EP one. In patients, only the EP condition differed from the other two (SP and ESP).

In the patients with TGA, unlike controls, the significance level was not reached in the SP condition. We believe that this absence of a priming effect was essentially due to a problem of statistical power (linked to the small number of patients with TGA), as semantic and perceptual priming effects have already been demonstrated in TGA (Beauregard et al., 1997; Eustache et al., 1997; Guillery et al., 2001; Kapur et al., 1996). Moreover, in our study, semantic priming effects were highlighted for negative words (ESP condition). This semantic 
priming effect limited to negative words in patients with TGA can be attributed to patients' depressive mood, which led them to pay greater attention to these particular items. In depression, authors have already postulated the pre-activation of negative nodes (Bower, 1981; Ingram, 1984). Thus, in patients who display a depressive mood, the strength of the links between semantically related concepts may be greater for negative items than for neutral ones, thus making it easier to highlight semantic priming effects for negative words.

Only the patients with TGA exhibited a significant priming effect in the EP condition. More specifically, we observed a reversed priming effect, that is, an inhibition effect, where negative primes led to longer RTs for negative targets. This inhibition effect (Fig. 2) can be likened to the interference effect described in the emotional Stroop task (Hermans et al., 2003), with participants tending to automatically allocate their processing resources to negative information (negative prime), which interferes with the processing of the ensuing target. More generally, in our study, negative primes systematically led to longer RTs for targets, across all conditions and groups. Other studies have shown that lexical decision times for negative stimuli are typically delayed, compared with neutral and positive stimuli, in both young (Rossell \& Nobre, 2004) and older individuals (Castner et al., 2007). Thus, negative stimuli are processed differentially because they are of major importance to the survival of the species. One of the mechanisms involved in the processing of negative stimuli consists in processing these stimuli (e.g., negative primes) more elaborately than other stimuli. This takes longer, and therefore delays the processing of subsequent information (Dijksterhuis \& Aarts, 2003; Pratto \& John, 1991). This phenomenon is called the negativity bias (Cacioppo \& Gardner, 1999). In the ESP and EP conditions in controls, and the ESP condition in patients, we still observed a classic priming effect (facilitation effect), but not so much as in the SP condition. As we saw above, the negativity bias led to an inhibition effect in the EP condition, but only in patients. We suggest that this result can be regarded as evidence of a mood 
congruency effect in TGA. As patients' mood at the time of examination was more depressed than that of controls, they were unable to ignore the negative information (which was not relevant to carrying out the lexical decision task), and this interfered with their responses for the targets (Sass et al., 2014). Patients' depressive mood may therefore increase the negativity bias. However, even if all patients displayed a sudden change in mood during TGA, all did not reach a pathological score (it concerned 3 of 9 patients) on the Bf-S scale. Thisheterogeneity could reflect the existence of several subgroups of TGA, among which an emotional arousal-induced TGA subgroup (Quinette et al., 2006). In this subgroup, the emotional impact of TGA could be more important (Noël et al., 2015) and therefore be responsible of mood congruency effect. In other words, it could be different cognitive profile of priming in TGA. Given the size of our patients' group, we were not able to compose to subgroups to confirm this hypothesis. This point is therefore a limit of our study. Other studies have highlighted mood congruency effects in implicit memory tasks in both nonclinically (Bradley, Mogg, \& Williams, 1994) and clinically (Dannlowski et al., 2006b) depressive individuals. Scott, Mogg, and Bradley (2001) demonstrated an automatic processing bias for negative information in a lexical decision task in dysphoric participants (individuals with a high score on the BDI, attesting to a depressive mood). In Dannlowski et al. (2006b)'s study, this mood congruency effect manifested itself in depressive patients as an inhibition effect in an emotional priming task. According to Bower's semantic network model of mood and memory (1981), activation of an emotion node leads to the automatic priming of mood-congruent material in memory. Ingram (1984) suggested that automatic activation along associative pathways within the depressive cognitive network is an essential element of depression, increasing the accessibility of negative representations (Teasdale, 1988).

[Insert Figure 2] 
Whereas the brain regions involved in cognitive impairments during TGA are better understood to date, those responsible for emotional changes are not clearly identified. Neuroimaging studies (Bartsch et al., 2006; Bartsch and Deuschl, 2010) have shown abnormalities limited to CA1 field of hippocampus which are supposed to explain the episodic memory deficits in TGA. Moreover, Bartsch et al. (2011) have also suggested that this profound transient impairment of hippocampus could lead to an acute diaschisis within the episodic and autobiographical memory network. Peer et al. (2014) have confirmed this hypothesis in showing a reduction in functional connectivity affecting the regions linked to hippocampus such as frontocingulate, inferior temporal, medial occipital regions, deep structures (thalamus, putamen and pallidum), but also others regions involved in episodic functioning and emotional regulation (amygdala and orbitofrontal cortex). On the contrary, the assessments of implicit memory such as the measurement of semantic priming effects are preserved in TGA. Indeed, the brain regions involved in semantic priming (particularly middle and superior temporal gyri which are associated with the concept's representation; Matsumoto et al., 2005; Giffard et al., 2008) are not disturbed in TGA. However, emotional priming effects were present only in TGA patients that we interpreted as a congruency mood effect. In their study, Leung et al. (2009) suggest that negativity bias (focus of attention on negative items) in depression might be related to a dysfunctional frontal-limbic connection. Besides, several studies (Davidson et al., 2002; Liotti and Mayberg, 2001) propose that prefrontal cortex, anterior cingulate cortex, amygdala and hippocampus are involved in depression. Thus, brain disconnections highlighted in TGA to explain the episodic memory disorders could be also responsible for the disturbance of mood during the episode.

To sum up, we have previously shown that TGA is accompanied by sudden changes in patients' emotional states, and that these modifications contribute to patients' impaired 
cognitive performances. The present study brings new and additional arguments in favor of a mood congruency effect in patients during the TGA episode. There is therefore an automatic processing bias for negative information in patients with TGA (inhibition effect in the EP condition), reflecting their depressed mood. Finally, affective priming is highly sensitive, and varies considerably (facilitation, inhibition or no priming) according to several factors. This study also suggests that the semantic link and mood must both be assessed and controlled for in future studies looking at affective priming. 


\section{References}

Baron, J.-C., Petit-Taboué, M.-C., Le Doze, F., Desgranges, B., Ravenel, N., \& Marchal, G. (1994). Right frontal cortex hypometabolism in transient global amnesia. A PET study. Brain, 117, 545-552. doi:10.1093/brain/117.3.545

Bartsch, T., Alfke, K., Stingele, R., Rohr, A., Freitag-Wolf, S., Jansen, O., \& Deuschl, G. (2006). Selective affection of hippocampal CA-1 neurons in patients with transient global amnesia without long-term sequelae. Brain, 129, 2874-2884. doi.org/10.1093/brain/awl248

Bartsch, T., \& Deuschl, G. (2010). Transient global amnesia: Functional anatomy and clinical implications. The Lancet Neurology, 9, 205-214. doi:10.1016/S1474-4422(09)70344-8

Bartsch, T., Döhring, J., Rohr, A., Jansen, O., \& Deuschl, G. (2011). CA1 neurons in the human hippocampus are critical for autobiographical memory, mental time travel, and autonoetic consciousness. Proceedings of the National Academy of Sciences of United States of America, 108, 17562-17567.

Beauregard, M., Weiner, J., Gold, D., \& Chertkow, H. (1997). Word priming during and after transient global amnesia. Neurocase, 3, 451-459. doi:10.1080/13554799708405021

Beck, A. T., Rial, W. Y., \& Rickets, K. (1974). Short form of depression inventory: Cross validation. Psychological Reports, 34, 1184-1186.

Bradley, B. P., Mogg, K., \& Williams, R. (1994). Implicit and explicit memory for emotional information in non-clinical subjects. Behaviour Research and Therapy, 32, 65-78. doi:10.1016/0005-7967(94)90085-X

Bower, G. H. (1981). Mood and memory. American Psychologist, 36, 129-148. doi:10.1037/0003-066X.36.2.129 
Cacioppo, J. T., \& Gardner, W. L. (1999). Emotion. Annual Review of Psychology, 50, 191-214. doi:10.1146/annurev.psych.50.1.191

Castner, J. E., Copland, D. A., Silburn, P. A., Coyne, T. J., Sinclair, F., \& Chenery, H. J. (2007). Lexical-semantic inhibitory mechanisms in Parkinson's disease as a function of subthalamic $\quad$ stimulation. $\quad$ Neuropsychologia, $\quad 45, \quad 3167-3177$. doi:10.1016/j.neuropsychologia.2007.06.019

Dannlowski, U., Kersting, A., Arolt, V., Lalee-Mentzel, J., Donges, U. S., \& Suslow, T. (2006a). Unimpaired automatic processing of verbal information in the course of clinical depression. Depression and Anxiety, 23, 325-330. doi:10.1002/da.20173

Dannlowski, U., Kersting, A., Lalee-Mentzel, J., Donges, U. S., Arolt, V., \& Suslow, T. (2006b). Subliminal affective priming in clinical depression and comorbid anxiety: A $\begin{array}{llll}\text { longitudinal } \quad \text { investigation. } & \text { Psychiatry }\end{array}$ doi:10.1016/j.psychres.2005.08.022

Davidson, R.J., Lewis, D.A., Alloy, L.B., Amaral, D.G., Bush, G., Cohen, J.D., Drevets, W.C., ...Peterson, B.S. (2002). Neural and behavioral substrates of mood and mood regulation. Biological Psychiatry, 52, 478-502. doi.org/10.1016/S0006-3223(02)01458-0

Dijksterhuis, A., \& Aarts H. (2003). On the wildebeests and humans: The preferential detection of negative stimuli. Psychological Science, 14, 14-18.

Eustache, F., Desgranges, B., Petit-Taboué, M.-C., de la Sayette, V., Piot, V., Sablé, C., ...Baron, J.-C. (1997). Transient global amnesia: Implicit/explicit memory dissociation and PET assessment of brain perfusion and oxygen metabolism in the acute stage. Journal of Neurology, Neurosurgery, and Psychiatry, 63, 357-367._doi:10.1136/jnnp.63.3.357 
Gardiner, J. M., Ramponi, C., \& Richardson-Klavehn, A. (2002) Recognition memory and decision processes: A meta-analysis of remember, know, and guess responses. Memory, 10, 83-98. doi:10.1080/09658210143000281

Giffard, B., Laisney, M., Desgranges, B., \& Eustache, F. (in press). An exploration of the semantic network in Alzheimer's disease: Influence of emotion and concreteness of concepts. Cortex.

Giffard, B., Laisney, M., Eustache, F., \& Desgranges, B. (2009). Can the emotional connotation of concepts modulate the lexico-semantic deficits in Alzheimer's disease? Neuropsychologia, 47, 258-267. doi:10.1016/j.neuropsychologia.2008.07.013

Giffard, B., Laisney, M., Mézenge, F., de La Sayette, V., Eustache, F., \& Desgranges, B. (2008). The neural substrates of semantic memory deficits in early Alzheimer's disease: clues from semantic priming effects and FDG-PET. Neuropsychologia, 46, 1657-1666.

Guillery, B., Desgranges, B., de la Sayette, V., Landeau, B., Eustache, F., \& Baron, J.-C. (2002). Transient global amnesia: Concomitant episodic memory and positron emission tomography assessment in two additional patients. Neuroscience Letters, 325, 62-66. doi:10.1016/S0304-3940(02)00233-1

Guillery, B., Desgranges, B., Katis, S., de la Sayette, V., Viader, F., \& Eustache, F. (2001). Semantic acquisition without memories: Evidence from transient global amnesia. Neuroreport, 12, 3865-3869.

Hainselin, M., Quinette, P., Desgranges, B., Martinaud, O., de La Sayette, V., Hannequin, D., ... Eustache, F. (2012). Awareness of disease state without explicit knowledge of memory failure in transient global amnesia. Cortex, 48, 1079-1084. doi:10.1016/j.cortex.2012.02.003 
Hermans, D., Spruyt, A., De Houwer, J., \& Eelen, P. (2003). Affective priming with subliminally presented pictures. Canadian Journal of Experimental Psychology, 57, 97-114.

Hodges, J. R. (1991). Transient amnesia. Clinical and neuropsychological aspects. London: W.B. Saunders.

Hodges, J. R., \& Warlow, C. P. (1990). Syndromes of transient amnesia: Towards a classification. A study of 153 cases. Journal of Neurology, Neurosurgery, and Psychiatry, 53, 834-843. doi:10.1136/jnnp.53.10.834

Ingram, R. E. (1984). Toward an information processing analysis of depression. Cognitive Therapy and Research, 8, 443-478. doi:10.1007/BF01173284

Inzitari, D., Pantoni, L., Lamassa, M., Pallanti, S., Pracucci, G., \& Marini, P. (1997). Emotional arousal and phobia in transient global amnesia. Archives of Neurology, 54, 866-873.

Kapur, N., Abbott, P., Footitt, D., \& Millar, J. (1996). Long-term perceptual priming in transient global amnesia. Brain and Cognition, 31, 63-74. doi:10.1006/brcg.1996.0025

Kincannon, J. C. (1968). Prediction of the standard MMPI scale scores from 71 items: The mini-mult. Journal of Consulting and Clinical Psychology, 32, 319-325.

Kritchevsky, M., Squire, R., \& Zouzounis, J. A. (1988). Transient global amnesia: Characterization of anterograde and retrograde amnesia. Neurology, 38, 213-219.

Laurent, B. (1991). Ictus amnésique. In Comité scientifique Recherche et mémoire, Mémoire, cerveau et astrocyte (pp. 43-47). Paris: Scientifiques Lehman Couturier. 
Leung, K.K., Lee, T.M., Yip, P., Li, L.S., \& Wong, M.M. (2009). Selective attention biases of people with depression: Positive and negative priming of depression-related information. Psychiatry Research, 165, 241-251. doi: 10.1016/j.psychres.2007.10.022

Lewis, P. A., Critchley, H. D., Smith, A. P., \& Dolan, R. J. (2005). Brain mechanisms for mood congruent memory facilitation. NeuroImage, 25, 1214-1223. doi:10.1016/j.neuroimage.2004.11.053

Li, J., Nilsson, L. G., \& Wu, Z. (2004). Effects of age and anxiety on episodic memory: Selectivity and variability. Scandinavian Journal of Psychology, 45, 123-129.

Liotti, M., \& Mayberg, H.S. (2001). The role of functional neuroimaging in the neuropsychology of depression. Journal of Clinical and Experimental Neuropsychology, 23, 121-136. doi: 10.1076/jcen.23.1.121.1223

Matsumoto, A., Iidaka, T., Haneda, K., Okafa, T., \& Sadato, N. (2005). Linking semantic priming effect in functional MRI and event-related potentials. NeuroImage, 24, 624-634. doi:10.1016/j.neuroimage.2004.09.008

Merriam, A. E., Wyszynski, B., \& Betzler T. (1992). Emotional arousal-induced transient global amnesia. Psychosomatics, 33, 109-113.

Néri, M., Andermarcher, E., De Vreese, L. P., Rubichi, S., Sacchet, C., \& Cipolli, C. (1995). Transient global amnesia: Memory and metamemory. Aging, 7, 423-429.

New, B., Pallier, C., Ferrand, L., \& Matos, R. (2001). Une base de données lexicales du français contemporain sur internet: Lexique. L'Année Psychologique, 101, 447-462. doi:10.3406/psy.2001.1341

Noël, A., Quinette, P., Dayan, J., Guillery-Girard, B., Piolino, P., Pèlerin, A., ... Eustache, F. (2011). Influence of patients' emotional state on the recovery processes after a transient global 
amnesia. Cortex, 47, 981-991. doi:10.1016/j.cortex.2010.10.003

Noël, A., Quinette, P., Guillery-Girard, B,. Dayan, J., Katis, S., Piolino, P., ... Eustache, F. (2007). How psychopathological factors affect both the onset of and recovery from transient global amnesia. Psychological Medicine, 37, 1673-1676. doi:10.1017/S0033291707001213

Noël, A., Quinette, P., Guillery-Girard, B., Dayan, J., Piolino, P., Marquis, S., ... Eustache, F. (2008). Psychopathological factors, memory disorders and transient global amnesia. The British Journal of Psychiatry, 193, 145-151. doi:10.1192/bjp.bp.107.045716

Noël, A., Quinette, P., Hainselin, M., Dayan, J., Viader, F., Desgranges, B., \& Eustache, F. (2015). The still enigmatic syndrome of transient global amnesia: Interaction between neurological and psychopathological factors. Neuropsychology Review. doi:10.1007/s11065015-9284-y.

Peer, M., Nitzan, M., Goldberg, I., Katz, J., Gomori, J.M., Ben-Hur, T., \& Arzy, Z. (2014). Reversible functional connectivity disturbances during transient global amnesia. Annals of Neurology, 75, 634-343. doi: 10.1002/ana.24137.

Pratto, F., \& John, O. P. (1991). Automatic vigilance: The attention-grabbing power of negative social information. Journal of Personality and Social Psychology, 61, 380-391.

Quinette, P., Guillery-Girard, B., Dayan, J., de la Sayette, V., Marquis, S., Viader, F., ... Eustache, F. (2006). What does transient global amnesia really mean? Review of the literature and thorough study of 142 cases. Brain, 129, 1640-1658. doi:10.1093/brain/awl105

Ramponi, C., Barnard, P. J., \& Nimmo-Smith, I. (2004). Recollection deficits in dysphoric mood: An effect of schematic models and executive mode? Memory, 12, 655-670. doi:10.1080/09658210344000189

Rossell, S. L. \& Nobre, A. C. (2004). Semantic priming of different affective categories. 
Emotion, 4, 354-363. doi:10.1037/1528-3542.4.4.354

Sass, K., Habel, U., Kellermann, T., Mathiak, K., Gauggel, S., \& Kircher, T. (2014). The influence of positive and negative emotional associations on semantic processing in depression: An fMRI study. Human Brain Mapping, 35, 471-482. doi:10.1002/hbm.22186

Schmidtke, K., \& Ehmsen, L. (1998). Transient global amnesia and migraine. A case control study. European Neurology, 40, 9-14. doi:10.1159/000007948

Schott, B. (1969). L'ictus amnésique. La Revue du Praticien, 19, 1205-1216.

Scott, K. M., Mogg, K., \& Bradley, B. P. (2001). Masked semantic priming of emotional information in subclinical depression. Cognitive Therapy and Research, 25, 505-524. doi:10.1023/A:1005541701832

Teasdale, J. D. (1988). Cognitive vulnerability to persistent depression. Cognition and Emotion, 2, 247-274. doi:10.1080/02699938808410927

Von Zerssen, D., Koeller, D. M., \& Rey, E. R. (1970). A scale for the objective evaluation of the state of subjective well-being as a method for longitudinal studies. Arzneimittelforschung, $20,915-918$.

Yeung, C. A., Dalgleish, T., Golden, A. M., \& Schartau, P. Reduced specificity of autobiographical memories following a negative mood induction. Behaviour Research and Therapy, 44, 1481-1490. doi:10.1016/j.brat.2005.10.011 
Table 1

Clinical and Demographic Characteristics of Patients with TGA

\begin{tabular}{|c|c|c|c|c|c|c|c|}
\hline $\begin{array}{c}\text { No. } \\
\text { patients }\end{array}$ & Age & Sex & $\begin{array}{c}\text { Duration } \\
\text { (hr) }\end{array}$ & Precipitants & $\begin{array}{c}\text { Assoc. } \\
\text { symptoms }\end{array}$ & Risk factors & $\begin{array}{c}\text { Bf-S scale } \\
\text { scores }\end{array}$ \\
\hline 1 & 73 & $\mathrm{M}$ & $>7$ & Gardening & PA: 2 & $\begin{array}{l}\text { Hyperchol, } \\
\text { AHT, heart } \\
\text { disease }\end{array}$ & 19 \\
\hline 2 & 52 & $\mathrm{M}$ & 7.5 & $\begin{array}{c}\text { Physical } \\
\text { effort }\end{array}$ & $\begin{array}{c}\text { PA: } 5 \\
\text { Headache }\end{array}$ & $\begin{array}{c}\text { Hyperchol, } \\
\text { AHT, } \\
\text { diabetes, PH }\end{array}$ & 30 \\
\hline 3 & 63 & $\bar{F}$ & 7.5 & $\begin{array}{l}\text { Extramarital } \\
\text { sexual } \\
\text { intercourse }\end{array}$ & $\begin{array}{c}\text { PA: } 6 \\
\text { Headache }\end{array}$ & AHT & 39 \\
\hline 4 & 63 & M & $>7$ & $\begin{array}{l}\text { Moving } \\
\text { house }\end{array}$ & PA: 1 & Hyperchol & $\mathrm{ns}$ \\
\hline 5 & 61 & $\mathrm{M}$ & 4 & Bad news & PA: 7 & Hyperchol & 16 \\
\hline 6 & 44 & $\bar{M}$ & 8.5 & Quarrel & PA: 0 & None & 18 \\
\hline 7 & 52 & $\bar{F}$ & 1 & $\begin{array}{c}\text { Sexual } \\
\text { intercourse }\end{array}$ & PA: 0 & Migraine & 20 \\
\hline 8 & 64 & $\mathrm{M}$ & 2 & None & PA: 0 & $\overline{\mathrm{AHT}}$ & 18 \\
\hline 9 & 51 & $\bar{F}$ & 1 & Quarrel & PA: ns & $\begin{array}{c}\text { AHT, } \\
\text { migraine }\end{array}$ & 27 \\
\hline
\end{tabular}

Note. No. $=$ number; hr $=$ hours; Ass. $=$ associated; PA: number of symptoms similar to panic attack; ns = data not supplied; Hyperchol = hypercholesterolemia; AHT = arterial 
hypertension; $\mathrm{PH}=$ psychiatric past history. The cut-off for depression signs on Bf-S scale is 27 
Table 2

Mean (Standard Deviation) Target Word Reaction Times (in Milliseconds) for Controls and Patients with TGA in the Lexical Decision Task

\begin{tabular}{|c|c|c|c|c|c|}
\hline Semantic relation & \multicolumn{2}{|c|}{ Unrelated words } & \multicolumn{3}{|c|}{ Related words } \\
\hline Prime valence & Neutral & Negative & Neutral & Neutral & Negative \\
\hline Target valence & Neutral & Negative & Negative & Neutral & Negative \\
\hline Controls & $1078(280)$ & $1085(278)$ & $1090(291)$ & $992(241)$ & $1049(252)$ \\
\hline TGA patients & 887 (222) & 927 (217) & $901(214)$ & $832(183)$ & 859 (188) \\
\hline
\end{tabular}


Figure 1

Mean Priming Effects in Milliseconds (error bars represent standard deviations) of the patients with TGA and the Controls in the Conditions of Semantic Priming (SP), of Semantic and Emotional Priming (ESP) and of Emotional Priming (EP)

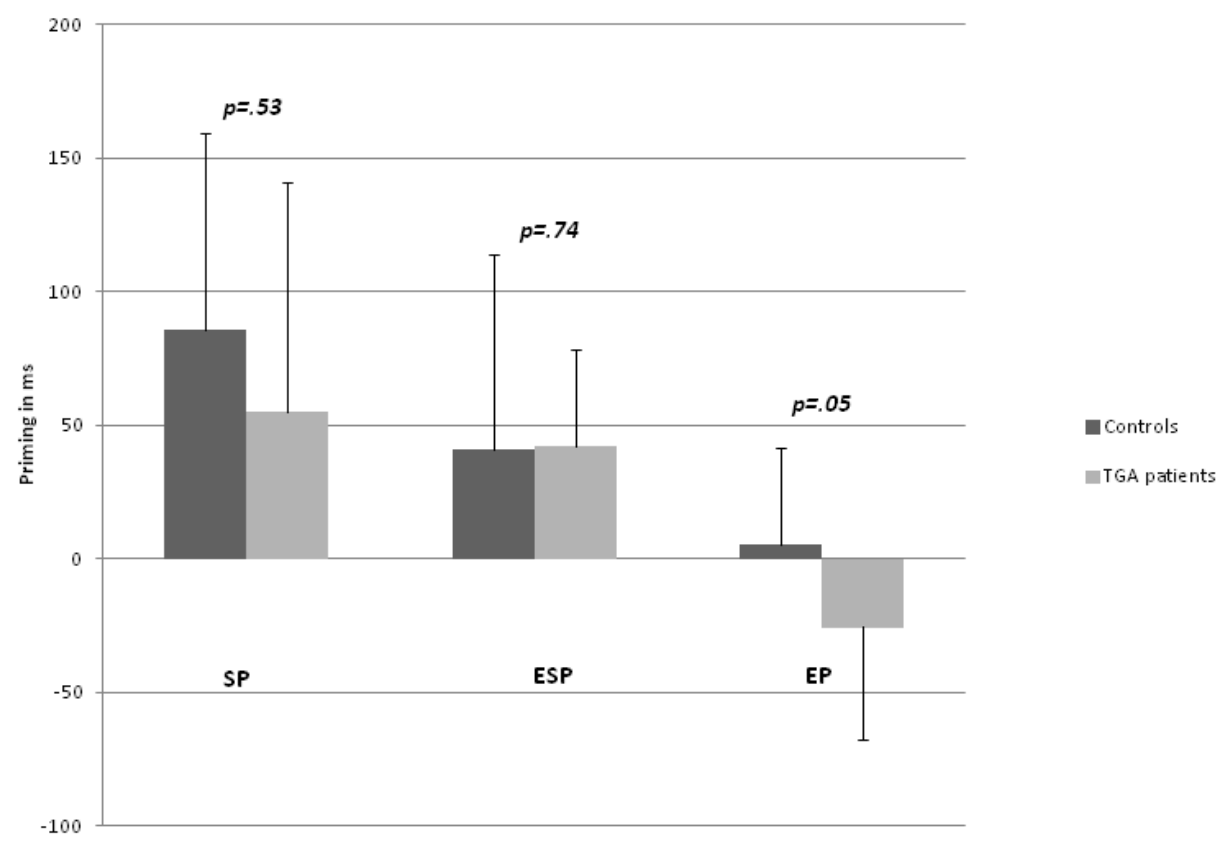


Figure 2

Design Representing Facilitation and Inhibition Effects in TGA, according to Priming Conditions
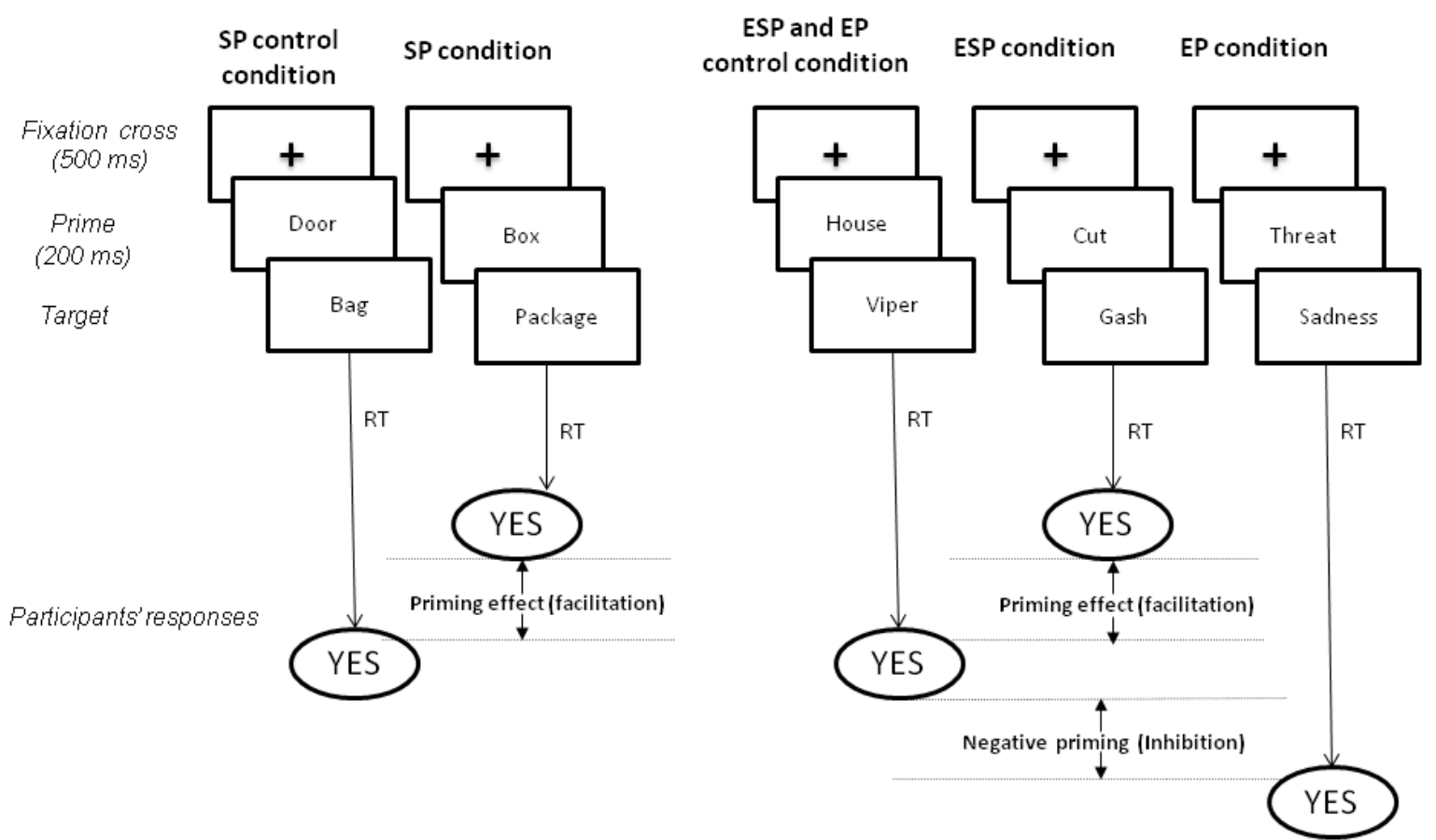

Note $. \mathrm{SP}=$ Semantic priming; $\mathrm{ESP}=$ Emotional and semantic priming $; \mathrm{EP}=$ Emotional priming; $\mathrm{Ms}=$ Millisecond $; \mathrm{RT}=$ Reaction Time 